\title{
PARTIDOS POLITICOS Y GOLPE DE ESTADO EN BOLIVIA. LA POLITICA NACIONAL-POPULAR DE BAUTISTA SAAVEDRA, 1921-1925
}

\author{
POR \\ MARTA IRUROZQUI VICTORIANO \\ Dpto. de Historia de América \\ CEH. Madrid
}

\begin{abstract}
«Frondosos discursos, programas de principios y de prácticas administrativas, declaraciones sobre libertad electoral, grandes escándalos de prensa, procesos judiciales ruidosamente explotados, todo ha servido para sugestionar a las masas y para reunir en un block revolucionario a todos los descontentos de la anterior situación" (1).
\end{abstract}

Tras la rebelión del 12 de julio de 1920, que supuso el fin del gobierno liberal iniciado en 1899, Bautista Saavedra asumió la dirección del Partido Republicano ahora en el poder. Desde un principio estuvo respaldado por los sectores dominantes de la ciudad de La Paz (2), teniendo en contra la opinión de los otros candidatos republicanos, el tarijeño José María Escalier y el cochabambino Daniel Salamanca. Ambos interpretaron el golpe de Estado protagonizado por Saavedra como una estratagema para obtener el liderazgo del partido (3), en vez de verlo como una medida destinada a terminar con el abuso electoral de los liberales (4). En consecuencia, Salamanca y Escalier decidieron unir sus

Proyecto I + D AME 90-0894-Co2-01. 1921.

(1) "La mascarada del republicanismo", El Diario, La Paz., 9 de enero de

(2) Eugenio Gómez, Bautista Saavedra (Seguido de El Ayllu, por Batsista Saavedra, Biblioteca del sequicentenario de la república, La Paz, 1975, págs. 111 116.

(3) El Diario, 24 de mayo de 1921.

(4) "Al fraude cínico puesto en práctica por las autoridades (liberales), a la compra escandalosa del voto, a la multiplicación infinita de cédulas electorales, se agrega el imperio de la violencia más ultrajante de la dignidad de los ciudadanos" en Bautista SaAviodra, Reforma Electoral, pág. XII, 1918. 
fuerzas en el Partido Republicano "Genuino", que pasó a la oposición después de fallar el acuerdo que Saavedra les propuso acerca de que fuera la Convención Nacional la que eligiese directamente al presidente (5). A pesar de ello el 23 de enero de 1921, la Convención confirmó como tal a Bautista Saavedra en una elección donde los votos a favor fueron de 47 y las abstenciones sumaron 36. En respuesta, se produjo un acercamiento entre republicanos "genuinos" y liberales que dio pie al presidente para adoptar poderes dictatoriales en previsión de un posible golpe de Estado y de una crisis política que podía agudizarse a causa de la declinación de los precios del estaño en el mercado mundial. Se iniciaba, así, otro momento de regeneración interna de la élite boliviana que tuvo como resultado el afianzamiento político, económico y social de la élite de La Paz.

Tanto la Guerra Federal de 1899 como el golpe de Estado de 1920 fueron acontecimientos que obedecían a necesidades de perpetuación y supervivencia de la élite (6) como grupo social. Si bien se trata de dos momentos de regeneración interna encaminados a evitar su agotamiento como clase dominante y en los que estaba en cuestión la continuidad del grupo privilegiado, el diseño de su jerarquía interna y la creación de formas más sólidas de control social que regularán el ascenso y participación

(5) GómEz [2] págs. 128-130; Alcides Arguedas, La danza de las sombras, 20 vol., Los amigos del Libro, La Paz, pág. 143).

(6) Con el término "élite" se pretenden rescatar muchas de las conceptualizaciones sobre movilidad y circulación de élites desarrolladas por téricos como Wilfredo Pareto, Gaetano Mosca, Robert Michels, Wright Mills y Thorstein Veblen, entre otros. Al mismo tiempo, resultan imprescindibles los análisis teóricos sobre estratificación y jerarquías sociales, imaginarios colectivos, partidos políticos y naturaleza del poder trabajados por Max Weber, Nobert Elías, Pierre Bourdieu, Maurice Duverger y Michael Foucault. Las discusiones presentes en estos textos permiten que a lo largo del artículo se de a la palabra "élite" el siguiente contenido. Se designa así a una clase social definida por su acceso al poder $y$ resultado del consenso que originan sus propias rivalidades cuando para dirimirlas recurren al apoyo y aspiraciones públicas de los sectores subalternos. Se trata de un concepto englobador de aquellos sectores sociales que se sit úan en la cima de las diversas jerarquías de prestigio, de poder y de propiedad, y de aquellos otros que constituyen su margen de reclutamiento y reserva. Cuando se habla de élite se hace referencia a un grupo social que, a pesar de su heterogeneidad, posec una herencia corporativa que proporciona a sus miembros una Tuerte cohesión social y psicológica. No constituye una unidad monolitica que actúa con consenso) interno y de modo coordinado en sus mutuas relaciones, pero se apoya frente a objetivos comunes con relación al poder. Su mavor debilidad son las comperencias personales y sectoriales. La constante neeesidad de defender sus actividades, propiedad y posición social en el espacio local y regional contra intereses rivales les obliga a una forzada intervención política a nivel nacional. En resumen, se trata de grupos de poder diversificados que se extienden a lodos los ámbitos del proceso de desarrollo y que gestionan intereses económicos muy variados. 
pública de los sectores subalternos, sus características varían. El triunfo del Partido Liberal frente al Conservador en la Guerra Federal de 1899 evidenció el fracaso del juego partidario de la continua renegociación del poder y de su acceso legítimo al mismo en cada elección, sobre todo una vez reducida la importancia del sustento económico que justificaba la preeminencia de Sucre. El resultado de estos acontecimientos fue dar a la voluntad de perpetuación de la élite una mayor oportunidad de estabilidad, gracias a que el dominio paceño aseguraba una construcción grupal más sólida debido a su mercado integrado y diversificado (7). A pesar de que no puede interpretarse la guerra civil de 1899 exclusivamente como un conflicto regional (8), si supuso una variación espacial y familiar de la élite, dando lugar a la sustitución de una fracción de esta - la sureña- por otra -la paceña-. En contrapartida, el golpe militar de 1920 encabezado por el Partido republicane no tenía la finalidad de intercambiar un grupo de élite por otro, sino de regenerar los cuadros dentro de la fracción de élite que había resultado hegemónica en 1899. La estrategia empleada para conseguirlo fue muy semejante a la usada por José Manuel Pando en el sentido de que se utilizó un discurso de contenido antioligárquico y se amenazó a la mancomunidad criolla-mestiza con la movilización de los grupos populares.

En este artículo se discute cómo la estrategia liberal de involucrar a los sectores subalternos en la definición de la hegemonía en el interior de la élite tuvo otra de sus manifestaciones en el régimen de Bautista Saavedra. No se pretende insistir en detalle sobre su desarrollo sino establecer una serie de hipótesis de trabajo que se apoyan en dos presupuestos interrelacionados: la coherencia discursiva manifestada por los sectores privilegiados permitió que las relaciones de poder no se mantuvieron únicamente mediante actos represivos, sino por medio de una política consensual que involucró a los sectores subalternos hasta el punto de hacerlos definidores de su propia subordinación. Sin adentrarse a analizar la del Estado durante la jefatura republicana, se quiere resaltar en los siguientes apartados, primero, el contenido de la propuesta de autonomía estatal de Bautista Saavedra; segundo, cómo el gobierno a través del discurso coopera-

(7) Marta Irurozoul, "El negocio de la politica. Indios y mestizos en el discurso la élite boliviana" en Fermín de PINo (comp.) Visión de si mismos y vision de los otros, CSIC. Madrid, 1994 (en prensa).

(8) Marta Irurozou, "Guerra de razas en Bolivia: la (re)invención de una ladición" c'n Revista Andina, n"20 págs. 166-18.5. 
tivista pretendía que el Estado se apropiara de todas las instancias de poder; y tercero, cómo éste asumió la representatividad de los grupos populares. Tales interrogantes conforman una pregunta más amplia referente al modo en que el Estado pudo hacerse presente en Bolivia.

Para finalizar, debe subrayarse el carácter provisional de las afirmaciones efectuadas en el trabajo que se presenta. Este debe ser considerado como una aproximación parcial que necesita ser complementada por otras investigaciones que puedan dar cuenta del complejo funcionamiento de los mecanismos de reproducción del poder.

\section{La propuesta de estado autónOmo de Bautista SaAvedra}

Habria hecho mucho más, si ustedes, los opositores hubiesen observado una conducta más patriótica, sirviendo de justo contrapeso al gobierno, pero dejándole libre y expedita su acción reconstructiva (9)

Los veinte años de dominio liberal (1899-1920), si bien asentaron el derecho de la élite paceña a la dirección del pais, también provocaron fuertes disensiones acerca de su supremacía perpetua. Los liberales al rechazar el federalismo, una vez concluida la Guerra Federal de 1899, incumplieron la promesa hecha a otras élites regionales de incorporarlas de manera beneficiosa a la dirección nacional. Este descontento ante una progresiva exclusión política que limitaba sus posibilidades en el mercado nacional e internacional y que, en consecuencia, la arrastraba a un "aplebeyamiento" y "provincialismo" de sus referencias culturales y modos de vida, dio origen a una oposición partidaria que aglutinaba a los disidentes. Pero, aunque el Partido Republicano encajaba como la alternativa de las élites desposeidas, defraudadas y relegadas por el gobierno, el golpe de Estado de 1920 no las llevó al poder sino revalidó la oferta liberal paceña. Bautista Saavedra no sólo continuó con la política de Ismael Montes (1904-1908, 1912-1916) sino que la regeneró dándole un nuevo impulso a partir de un presupuesto básico: la autonomía del Estado.

Con la intención de que el Estado no fuese más un instrumento pasivo al servicio de la clase dominante sino que pasara a convertirse en el árbitro e intermediario de sus conflictos internos,

(9) Carta de Bautista Saavedra a José María Escalier, 27 de septiembre de 
la élite paceña dejó de lado su apariencia de élite regional y adquirió un matiz nacional, a la vez que $\mathrm{La}$ Paz pasó de ser la sede de la élite hegemónica a la de un gobierno representativo de todos los departamentos del país. Con ésto se pretendía, primero, deslegitimar políticamente las protestas regionales a las que se acusó de estrechez pueblerina y, segundo, impedir que el país se convirtiera en el monopolio de un único gnupo económico, los mineros del estaño, como en parte ya había ocurrido en el periodo conservador con los empresarios de la plata. Ambos objetivos iban encaminados a dar una oportunidad al partido político en el poder de concluir con el proyecto de reconstrucción oligárquica (10).

Como la etapa conservadora y liberal habían evidenciado que ninguna de las fracciones de la élite estaba dispuesta a ser la fracción excluida y sacrificada, la solución a ese desacuerdo, que ponía en peligro su perpetuación como clase, consistía en que la elección de la élite hegemónica no debía provenir ni ser impuesta por una de ellas, sino a través de una institución de rasgos globales, es decir, por el Estado. Si se quería resolver el problema de la élite se hacía preciso configurar a éste como entidad autónoma. Por este motivo, durante el gobierno republicano se vio acentuada la problemática élites-Estado que había empezado a manifestarse desde el abandono del federalismo tras la guerra de 1899 (11). Con esto la pugna entre el poder central y los poderes regionales se agudizó mucho más debido a que se interpretó que la élite hegemónica no era resultado de un consenso más o menos forzado entre élites sino que nacía de una imposición de la hasta entonces en el poder que para mantenerse en él se transformaba en Estado. A pesar de esas reticencias de las élites regionales, que tuvieron su representación parlamentaria en el Partido Republicano Genuino de Daniel Salamanca y José María Escalier, la idea de un Estado autónomo fue viable en la medida en que Bautista Saavedra utilizó, como ya lo hiciera en la década de 1890 el coronel Pando (12), el apoyo de los grupos populares cooptados a su causa a través de las clientelas políticas. La amenaza india fue sustituida por la amenaza proletaria-mestiza y la "guerra de razas" se convirtió en «lucha de clases». Si antes

(10) Marta Irurozoui, Elites en litigio. La venta de tierras de comunidad, 1880-1899, Lima, Documento de trabajo (DDT), IEP, 1993.

(11) Marta Irurozoui, Poder y élites en Bolivia Partidos políticos, imaginarios colectivos y proyectos nacionales. Tesis doctoral, Madrid, 1992, Universidad Complutense (en prensa).

(12) Idem. 
había miedo a una rebelión general de la indiada que invirtiera la estructura étnica (13), ahora se temía una revolución que desmantelara el orden social. Esta continuidad del miedo fue instrumentalizada por Bautista Saavedra en favor de fortalecimiento del Estado, repitiéndose la estrategia liberal de amenazar con el retorno del caudillismo (14). Este régimen no fue ni democrático ni libertario, pero su inestabilidad implícita si permitió el acceso al poder a grupos tradicionalmente excluidos de él debido a la inexistencia de un control institucionalizado de la movilidad social. Y esta ausencia constituía uno de los mayores miedos de cualquier fracción de la élite porque comprometía directamente su supervivencia grupal. Ante tal peligro, un Estado autónomo podía soportarse si regulaba el ascenso social de los grupos subalternos en beneficio de la élite, aunque el control y supervisión de ésta también formara parte de su jurisdicción.

Puede interpretarse que la opción estatal escogida por Bautista Saavedra respondía a una situación política personal, sin demasiados partidarios entre los sectores dominantes del país, incluso entre los paceños, y con un partido fraccionado al que amenazaban continuamente sus antiguos miembros. Sin embargo, la institucionalización de un Estado autónomo, árbitro de las relaciones intra-élites e intermediario entre ésta y los sectores subalternos, favorecía en última instancia el proyecto de reconstrucción oligárquica. Al asumir el Estado el arbitraje en el interior de los grupos privilegiados, se hacía cargo también de la razón que lo hacía necesario, esto es, el intervencionismo estatal institucionalizaba el proyecto de reconstrucción de la élite, lo convertía en su propio fin y le daba una dimensión nacional. A pesar de esa ventaja, el desacuerdo regional permanecía al igual que las rivalidades y personalismos partidarios. Con ello, la situación de la élite se mantuvo en una continua indefinición que la desgastaba y que a la vez permitía que los sectores subalternos fueran adquiriendo presencia política mediante el empleo de canales estatales. Por tanto, si la autonomía del Estado respecto a una fracción de élite podía favorecer a toda ella en su conjunto, en la práctica, a través de las clientelas y la consiguiente burocratización de éstas, fueron los grupos subalternos los que tuvieron una mayor oportunidad de expresión política. Esto se evidencia en el discurso politico cada vez más democrático tanto oficial como de la oposición.

(13) Irurozoui, [8], págs. 193-197.

(14) Idem. 


\section{El discurso cooperativista de Bautista SaAvedra}

La doctrina liberal, haciendo del individualismo, el principal motor de las actividades sociales, fue, sin duda, causa sino determinante, estimuladora del profundo desequilibrio a que han llegado, en una evolución paralela, el capital y el trabajo. Las clases desheredadas, el proletariado, al frente de las opresiones del capital, no pudieron menos que convencerse de que las libertades individuales, por las que tanto habían luchado las generaciones pasadas, creyendo encontrar en ellas la redención de todas las servidumbres, no habían servido para otra cosa que para someterlas a una otra esclavitud mayor y más desesperante, cual es la servidumbre económica (15).

El discurso político desarrollado por el Partido Republicano partía del rechazo del liberalismo, ideología estandarte del Partido Liberal. A los presupuestos de libertad y soberanía individual se oponía la soberanía social que comportaba deberes de solidaridad y cooperación (16). Se manejaba, por tanto, por parte de los republicanos una mixtura discursiva del ideario socialista y anarquista que hacía especial hincapié en el rechazo del individualismo como una fuerza disociadora del bienestar social. Para que los derechos individuales estuviesen resguardados y no entraran en contradicción unos con otros era necesaria la presencia de un Estado que, dejando a un lado los intereses particulares, rescatara la energía nacional:

La misión del Estado no es otra cosa que una perpetua transacción o concordancia entre el ideal individual que pugna por salirse de su esfera y el ideal colectivo y político que tiende a centralizar, unificar los distintos sentimientos aislados de los particulares, todo para el bien y progreso de la patria (17).

En nombre de un ideario de conservación de la tranquilidad social y política, se proponía la existencia de una institución que estuviese por encima de los partidos y de los derechos ciudadanos. Es decir, se estaba abogando por depositar el arbitrio del conflicto intra-élites en un órgano aséptico que buscara la supervivencia y continuidad de las relaciones de dominación y que

(15) Bautista SaAvedra, La democracia en mestra hisloria, 1921 en Gómez, [2], pág. 144.

(16) "La uposición", La República, La Paz, 7 de junio de 1923.

(17) Idem. 
fuese capaz de superar las rencillas regionalistas de los sectores privilegiados para lograr una nación que los representase con el grado de modernización y progreso que pretendían. Pero esto sólo sería posible si se acordaba que el Estado tenía «iguales o quizás superiores prerrogativas que el individuo" (18). Si esto se admitía, la estabilidad de la vida colectiva estaría garantizada frente a las agitaciones privadas ya que una mayor presencia del Estado en el orden de la nación era la medida para «librar a la nacionalidad de los desbordes de la anarquía (19). La centralización constituía el paso siguiente y definitivo para que el consenso intra-élite buscado por Bautista Saavedra a partir de la concesión de prerrogativas autónomas al Estado, fuese un hecho. Ello provocó, a su vez, que el discurso político oficial republicano llevase implicito un rechazo del regionalismo (20). Este, si bien se interpretó por parte del gobierno como negación y oposición a la necesaria actividad centralizadora del Estado, significaba la resistencia a que el consenso intra-élites se realizara a partir de las relaciones de poder vigentes durante la fase liberal, esto es, a partir de la hegemonía paceña.

Las líneas del nuevo modelo económico de los republicanos eran la diversificación en lo económico y la integración en lo político y social. Esa integración significaba desde el comienzo una subordinación del país a la dinámica de mercado del departamento de La Paz, porque el aparato del Estado había centralizado su acción en esta ciudad. Al concebirse el Estado como el encargado de centralizar el desarrollo nacional frente a una élite segmentada se lo estaba considerando como una instancia de negociación, de lucha entre fracciones de la clase dominante por su utilización exclusiva. Es quizás por esto que el Estado se convirtió en el actor más importante de los problemas regionales. Estos llegaron a ser, así, una expresión de la lucha entre fracciones de la élite por controlar la orientación de la economía. La política del país estaba muy mediatizada por la conquista de parcelas del Estado, de lo que resultaba que la capacidad política de la élite paceña procedía de su capacidad de copar el aparato del Estado como élite nacional. De ahí que los intereses de La Paz fueran más de hegemonía nacional que local. En consecuen-

(18) “Menos política y más administración", La República, La Paz, 7 de junio de 1923

(19) "La nueva tendencia", La República, La Paz, 14 de jumio de 1923.

(20) "...existe la pasión oscura, irreflexiva del regionalismo que ha hecho a Bolivia más daño tal vez que ninguno de los otros países". "Nacionalismo", La República, La Paz, 25 de agosto de 1921. 
cia, se combatía el centralismo del Estado porque se cuestionaba la continuidad de la élite paceña como hegemónica. Pero tras la Guerra Federal de 1899 y el golpe de Estado de 1920, su supremacía ya no provino más de si misma y de sus diversificadas actividades económicas sino del hecho de que el Estado se instaló definitivamente en dicha ciudad. Este Estado centralizado se convirtió, entonces, tanto en un lugar de enfrentamientos regionales como en el creador de desigualdades regionales (21). De este hecho se desligó que el proyecto centralizador del Estado se enfrentase a dos tensiones fundamentales presentes hasta hoy día: la de las regiones abandonadas y que se convierten por ello en la negación del desarrollo que ambiciona el gobierno, y la de las regiones cuyo desarrollo se ve «sofocado» por las prioridades de éste. Frente a tales tensiones se originó durante el período republicano el diseño de un Estado nacional-popular que luego fue asumido como propio por las corrientes progresistas que convergen en la revolución de 1952.

3. EL «NUEVO INDIO»: EL PROLETARIADO MINERO E INDUSTRIAL

El trabajo entre nosotros ni está debidamente organizado en defensa de su propia causa ni están los trabajadores unidos en el mismo ideal (22).

El discurso de lo nacional-popular empleado por Bautista Saavedra estuvo referido a la captación de los sectores subalternos come fuerza de choque que garantizara el éxito de las medidas gubernamentales sobre las discrepancias regionales. Se pretendió hacer del Estado una institución capaz de concentrar todos los mecanismos para canalizar los conflictos: la máxima concentración del poder frente a la máxima organización laboral. Esta ambición en ningún caso se proponía favorecer a los grupos populares sino forzar la adhesión de las élites desposeídas al proyecto estatal. Por este motivo, aunque fue durante el gobierno

(21) José Bl.anes. "El Estado y la región en La Paz", en Fernando CaLderón y Roberto LASERna (comps.), El poder de las regiones, Cochabamba, CERESCLACSO, 1985, págs. 69-73.

(22) Bautista SaAvedra, Manifiesto divulgador del Programa republicano socialista, La Paz., 1935. 
de Saavedra cuando se legisló en favor de la mejora de las condiciones laborales de los obreros (23), la fórmula escogida para que los estratos sociales más bajos coadyudaran al asentamiento de un Estado autónomo fue el clientelismo. A pesar de las numerosas críticas vertidas por parte de los partidos de oposición contra su uso, el clientelismo estabilizaba las relaciones de poder porque conducía la participación popular por canales ilegítimos, por vías que hacían depender su presencia pública de una relación paternalista con el jefe del partido. Si bien lo popular actuaba políticamente lo hacía en "función de", "bajo el permiso de», "dirigido por", "con la aquiescencia de», es decir, su presencia se regulaba desde arriba de modo que no podía sustraerse a los móviles de las élites. El clientelismo garantizaba a éstas un uso controlado de la amenaza de lo popular, con lo que la lucha en el interior del grupo privilegiado se convertía en la lucha de sus respectivas clientelas partidarias. Por ello, cuando este sistema era rechazado en el parlamento y en la prensa, no se buscaba tanto su desmantelamiento sino desvirtuar el monopolio que hacia de él el Partido Republicano. El problema se hacía más acuciante en la medida en que Saavedra desarrollaba un centralismo clientelístico que intercambiaba la lealtad a su partido por la lealtad al Estado. Esta acción se reforzaba con la conversión de los poderes locales en estructuras centrípetas de apoyo al gobierno que ayudaran a forzar un consenso intra a favor de un poder centralizado. La estrategia empleada por Saavedra consistía en ampliar su margen de clientelas a partir de un discurso de reconocimiento público de la capacidad política de un proletariado incipiente. Al ver reconocida su presencia desde el Estado y no sólo en nombre de un partido, estos sectores subalternos creían en la legitimidad y protección pública que Saavedra les otorgaba, ampliándose el margen de su reclutamiento y la consiguiente ventaja de los republicanos para forzar un acuerdo entre el Estado y las facciones de élite de la oposición. A pesar de ello continuaba latente la amenaza de la instrumentalización de la fuerza y descontento clientelar por parte de los desposeidos de la élite, esto es, de la oposición política.

El comportamiento integrador del gobierno buscaba neutralizar las oposiciones intra-clases que amenazaran la continuidad de la élite paceña en la dirección del país. Para ello, el gobierno

(23) Gòmt:., [2], págs. 200-202. 
republicano reconoció discursivamente que no sólo durante el período liberal el indio-campesino-trabajador fue objeto de la crueldad del terrateniente, del corregidor y del cura, sino que ahora indios y obreros resultaban víctimas de lo mismo (24), aunque con una diferencia, el Estado los protegía:

El gobierno que rige hoy los destinos nacionales es eminentemente democrático y amigo de las clases trabajadoras. Para los obreros alberga las mejores intenciones, y alienta los propósitos más firmes y sinceros para orientar siempre su política de acuerdo con el bienestar del pueblos (25).

Frente al período anterior en que las denuncias provenían de parte de la Iglesia (26) y de los intelectuales (27), ahora eran las instancias oficiales las que reconocían la explotación y proponían corregirla. Con ello, el Estado retomaba la tutela y protección de los grupos subalternos, los apadrinaba $y$, en consecuencia, les hacia delegar sus resistencias al buen saber del gobierno establecido. De esta forma, no sólo se invalidaba la legitimidad de organizaciones obreras y campesinas, subrayándose su sinrazón, sino que se afirmaba el crecimiento del Estado como la finalidad lógica de su comportamiento. Por otra parte, la función protectora asumida por el Estado, al rescatar antiguas formas de convivencia, expresadas en el pacto de reciprocidad entre el Estado y las comunidades indígenas, que ahora se ampliaba a uno entre el Estado y los ciudadanos, le hacía ser reconocido por éstos como la instancia legal que restituía sus derechos frente a la política practicada por los conservadores y liberales entre 1880 y 1920 (28). Es decir, el Partido Republicano se adueñó de la tradición estatal de asumir la tutela del universo popular tanto para

(24) "Triunfo de la causa popular y nacional", La Repriblica, La Paz, 13 de julio de 1921. "Los sucesos de Llallagua y Uncía". Los obreros agradecen el intervencionismo del gobierno", La Repriblica, La Paz, 13 de junio de 9923.

(25) "La próxima huelga revolucionaria", La Repuiblica, La Paz, 23 de agosto de 1921.

(26) Marta Inukozovi, "La pugna por el indio. Los liberales y la iglesia en Bolivia, 1900-1920", Ponencia presentada al IV Coloquio Internacional Evangelización, religion v cultura e'n los Andes, CLACSO-CBC, 1992 y publicada en Gabricla Ramos (comp.) la venida del Reino. Evangelización, réligión y culutra e'n América, siglos XVI-XX. Lima, CBC, 1994.

(27) Marta Irurozou, "¿Qué hacer con el indio? Un análisis de las obras de Alcides Arguedas y Fran\%. Tamavo?", en Revisia de Indias, no 195/196, CSIC, Madrid, 1992 e InUR()zoul|7|.

(28) Malta IRURozoul, "Las buenas intenciones. Venta de tierras comunales en Bolivia, 1880-1899", ponencia presentada al Coloquio Internacional Indios, comminidad y Nación èn América latina, sigho XIX, INAH-CONDUMEX, México, 1993. 
descalificar las acciones pasadas y presentes del grupo opositor, como para desacreditar los anhelos y las formas de organización subalternas.

Pero el objetivo de Saavedra no era dominar a los grupos populares en si, sino regularlos con el propósito de controlar a la élite opositora. Es decir, el aparente conflicto entre clases estaba supeditado al enfrentamiento intraclases. Mediante la denuncia de que los hacendados maltrataban a sus colonos y peones, creándoles resentimiento y obligándoles a sublevarse, se pretendía descalificar políticamente a los propietarios. Se decía que no sólo malgastaban y embrutecían su mano de obra tornándola peligrosa para la colectividad, sino que no hacían un uso correcto de sus posesiones agrícolas ya que dejaban sin cultivar sus tierras y no pagaban los impuestos correspondientes. No había, por tanto, un aprovechamiento industrial de la riqueza con lo que se perdían los beneficios sociales. Y como éstos eran objetivos prioritarios en el discurso político republicano sobre las razones por las que el Estado debía fortalecerse, se deslegitimaba en favor del gobierno la propiedad de los particulares que no participaban de la reforma nacional. El Estado, entonces, podía forzar su mejora y en caso extremo hacerse con las tierras siempre que con eso se lograra un aumento del bienestar de la colectividad (29). En realidad, en ningún caso iba a llegarse a expropiaciones pero resultaba conveniente esa amenaza como medida de fuerza que hiciera cada vez más presente al Estado como supervisor del país, sobre todo cuando la agricultura se convertía en la mayor riqueza de Bolivia por la crisis en la minería (30). Además, los hacendados como poderes locales podían presionar en contra del gobierno, con lo que este también les aconsejaba no hacerlo a través de la instrumentalización estatal del descontento campesino y proletario, al tiempo que los animaba a apoyar cualquier decisión del ejecutivo. Por tanto, no estaba tanto en juego el control de lo económico como de lo político.

A pesar de estas estrategias del poder central encaminadas a neutralizar a la oposición política, y pese a los discursos misericordiosos y protectores hacia los estratos dominados, quienes en última instancia sufrían la represión eran estos últimos. Por mucho que se acusara a los liberales y a los republicanos genuinos de sublevar a las masas para crear un clima de caos y apropiarse nuevamente del poder a partir de la instrumentaliza-

(29) "El Latifundio", La República. La Paz., 7 de septiembre de 1921.

(30) "El problema agrario", La República, La Paz, 27 de septiembre de 1921. 
ción del descontento y apoyo popular (31), se encarcelaba y mataba a los obreros y los campesinos sublevados (32). La justificación oficial radicaba en que esto ocurría porque los grupos menos privilegiados habían abusado de las ventajas laborales ofrecidas por Saavedra atentando contra la colectividad social (33). El bienestar colectivo era, por tanto, la idea base de un régimen político que colocaba al Estado como garante del proyecto de hegemonía de la élite. Este, para disminuir el desgaste entre las distintas fracciones de ésta, elaboró un discurso nacional-popular que mantuvo en el ideario colectivo la imagen de brutalidad e incapacidad de los grupos subalternos para evitar que este se convirtiese en un canal para su representatividad política.

El referente volvía a ser la masacre de Mohoza (34) aunque esta vez transfigurado en un asalto a la familia Vilela en Achacachi (35). En la madrugada del 13 de julio de 1920, se produjeron en esta localidad enfrentamientos con motivo del Golpe de Estado republicano. Los hechos referentes al doble asesinato ocurrieron con ocasión del traslado de algunos cadáveres de policías, por un grupo de vecinos del pueblo, comandados por Mariano Imaña, al hospital que se encontraba cercano a la casa de la familia Vilela. A su paso por este domicilio atacaron a la señora Vilela, que estaba en el zaguán de la casa, acusándola de pronunciarse a favor de la causa de los muertos. Ante los gritos, su esposo que estaba enfermo bajó al portal armado de una pistola (36). Se inició, entonces, una lucha a la que se fueron sumando otras

(31) Gómez, [2], págs. 199.

(32) "Me encontré con hechos producidos sin que hubiera estado en mis manos el poder no sólo evitarlos, ni siquiera preeverlos, pero cargando, sí, con las responsabilidades de éstos" (Bautista SAavedRA, Palabras sinceras, editions "Le livre libre", Paris, 1928, pág. 91).

(33) "Prejuicios que acarrean las huelgas", La República, La Paz, 15 de junio de 1923 .

(34) En la Guerra federal de 1899 que enfrentó a liberales con conservadores participaron grupos indígenas aymaras del Altiplano como ejército auxiliar de los primeros. Si bien bajo el permiso de los liberales los indios llevaron a cabo el exterminio de batallones unitarios en Ayo Ayo y Corocoro, en el caso de la matanza en Mohoza las víctimas fueron liberales, es decir, miembros del bando al que los indigenas decian apoyar. Se trató de un batallón liberal, el batallón Pando, que tras haber pasado un día en el pueblo de Mohoza, provincia de Inquisivi, fue retenido en su marcha y conducido a la iglesia donde se ejecutó cruelmente a todos sus miembros, celebrándose más tarde rituales en los que se practicó la antropof agia (IRUROzoUI, 8 y 26).

(35) "La espantosa masacre de la familia Videla en Achacahi. El Diario, La Paz., 10 de marzo de 1921.

(36) Daniel M. Vilela, era un abogado liberal que ejercía como juez instructor en el distrito. 
personas, en su mayoría parientes de Imaña, y cuyo resultado fue la muerte de los esposos Vilela, siendo sus hijos testigos de tal acto. Sus cuerpos fueron vejados, descuartizados y arrastrados hasta la plaza después de haberse saqueado su domicilio y el almacén de abarrotes que poseían. Los cadáveres, quemados con kerosene, permanecieron allí hasta que al atardecer los condujeron al cementerio donde las autoridades prohibieron que fueran sepultados.

Cuando estos acontecimientos se hicieron públicos, se utilizaron para definir el delito las mismas alusiones a la ferocidad, salvajismo y bajos instintos de las clases populares empleadas con anterioridad para describir la matanza de Mohoza (37):

Achacachi, desde los primeros años de la república y aún en tiempos posteriores fue teatro donde campearon los tipos más feroces, criminales de toda laya; sin faltar el detalle menor a la catalogación de Lombroso o Spencer, y a otros criminólogos que han observado de cerca estos fenómenos patológicos.

Entretanto se cometían estos atentados de lesa civilización a pocas leguas de la ciudad de La Paz, en medio de algarabía canibalesca, ahí mismo las furiosas mujeres, querían acabar con los niños huérfanos de la familia Vilela.

Las hienas humanas procedieron al festín rojo, sobre cadáveres, saboreando su criminalidad impúdica viscera por viscera; hasta llegar a los órganos generadores con un instinto indomeñable de saciar esa sensualidad de sangre inextinguible.

Enagenadas estas ménades, furiosas de bilis y alcohol, balbuciendo extraña gerigonza, mezcla confusa de aimara y castellano con las bocas preñadas de coca y maldiciones, se entregaron a los más refinados actos de crueldad primitiva (38).

A pesar de las coincidencias verbales en las referencias al canibalismo y a la falta de instrucción, asi como la interpretación del asesinato como una fiesta popular en la que a través del consumo de coca y alcohol se manifestaban pasiones políticas, la principal diferencia con lo sucedido en Mohoza residió en la filiación étnica de los participantes. Esta vez los asesinos no eran indios aymaras sino trabajadores mestizos de la empresa familiar. Además, si bien en ambos casos se cometían los crímenes al amparo de un conflicto nacional, la Guerra Federal de 1899 o el Golpe de Estado del 12 de julio de 1920 respectivamente, en la

(37) IRUROZOUI [8] y [23].

(38) Luis F. Vilei.A del. V. "13 de julio”, La Paz, 1929, págs. 16, 43, 48-49. 
primera ocasión las víctimas habían sufrido una traición partidaria, mientras que en la segunda se reafirmaba el apoyo de una clientela política a su líder. $Y$ en tal distinción residía la distinta suerte que tuvieron los participantes en uno u otro conflicto. Terminada la guerra civil de 1899 los cabecillas de la sublevación de Mohoza fueron encarcelados a la vez que se realizaba una campaña represiva sobre la mayoría de comunidades indígenas del Altiplano. Por el contrario, los responsables de lo ocurrido el 12 de julio quedaron exculpados ante el descontento de la oposición política a Saavedra, que continuaba reclamando en $1929 \mathrm{su}$ condena:

Esos esbirros pueden asegurar que están en el mejor de los mundos, porque el gobierno los socapa. Lejos de enviarlos a la cárcel o la disposición de la justicia, los transforma en sus instrumentos ciegos para fomentar la delincuencia, el matonaje, el descaro y la infidencia. Varios de estos, casi en su mayoría, antes del 12 de julio, estaban en la penitenciaría (39).

A partir de lo expuesto hasta ahora, referente al origen mestizo y a la actividad clientelar llevada a cabo por Mariano Imaña y sus parientes, puede establecerse un esquema hipotético acerca de la estrategia de poder que desarrolló Bautista Saavedra para neutralizar los efectos del conflicto intras que se iniciaba con su presidencia. Primero, potenció la autoridad y libertad de sus clientelas políticas con el fin de maniatar las acciones de sus opositores. Segundo, aunque su gobierno no se caracterizó por reprimir los desmanes de sus adeptos si utilizó el discurso de brutalidad mestiza e india (40), que se desarrollaba a partir de los abusos criminales de los primeros, para justificar actos represivos contra organizaciones obreras y campesinas. Es decir, por un lado, permitió el desarrollo de la informalidad política para debilitar las pautas partidarias tradicionales y crear un marco de dependencias políticas que favoreciesen la centralidad y autonomía del Estado; y por otro, concientizó a los miembros de la comunidad criollo-mestiza del peligro que suponían los sectores populares, haciéndola consciente del poder del mismo Saavedra

(39) Idem.

(40) “... para que comprenda cuán erróneo está al pensar que es libre, y para que se aparte de aquellos que aprovechan de su característica psicológica, para servir sus intereses personales", ldem, pág. 12. 
en el desarrollo o reducción de su violencia (41). En consecuencia, el clientelismo no cuestionaba la jerarquía de poder tal como se practicaba hasta entonces, sino que buscaba hacerla más tolerable y con ello más resistente a las presiones de remodelación en nombre de la justicia social. Si bien permitió a los sectores subalternos canalizar y hacer presentes sus ambiciones públicas, también redujo su derecho legítimo a la dirección del país, ya que redujo su papel al de intermediarios. Para el gobierno, la amenaza de los sectores populares era más grave que durante el régimen liberal y claramente más independiente de la manipulación política por parte de la oposición elitista. Por ello, Saavedra entremezcló el paternalismo clientelar con una política represiva. Esta se manifestó con mayor virulencia sobre el campesinado indigena (42) que sobre los sectores proletarios, como lo prueba el hecho de que el presidente se negara a considerar ninguna reforma rural y prefiriese mantenerse en las posiciones tradicionales de desprecio hacia lo indio que había demostrado en el Juicio de Mohoza (1901-1904) (43), como ocurrió al enviar tropas para aplastar la sublevación india de Jesús de Machaca en 1921 (44).

En resumen, la campaña de prensa iniciada por El Diario denunciando el crimen de la familia Vilela evidenció la necesidad de la mancomunidad criolla-mestiza de mantener ciertos mitos sangrientos para coartar posibles traiciones de clase, a la vez que legitimó posibles acciones del ejército contra obreros y campesi-

(41) “...buscamos otra orientación, apartándonos de los dogmas políticos que han enervado el organismo nacional. Para curar las lacras del pueblo, debemos dejar primeramente la ominosa tutela. Porque no solamente debemos señalar como causa original las influencias raciales, sino también las fuertes subordinaciones populares a intereses políticos privilegiados". Idem, pág. 10.

(42) La represión se combinó con una ley, de valor más formal que real, promulgada el 8 de enero de 1925 que determinó la enajenación de tierras de origen en subasta pública y prohibió su hipoteca convencional y el embargo y remate en ejecución de obligaciones personales de sus poseedores (Sobre el proceso de implantación de la ley consúltese Nota de Bautista Saavedra al Presidente del Senado, 7 de agosto de 1923 y GómEz [2], págs. 225-232.)

(43) Bautista SaAvedra, Proceso Mohoza. Defensa del abogado Bautista Saavedra pronunciada en la audiencia del 12 de octubre de 1901, La Paz, Tipográfica Velarde, 1902. "La criminalidad aymara en el proceso de Mohoza", en Bautista Saavedra, El Ayllu, La Paz, 1903.

(44) James DunKerLey. Orígenes del poder militar en Bolivia. Historia del Ejército, 1879-1935. La Paz, Editorial Quipus, 1987, págs. 78-108. Herbert KLEIN, Origenes de la Revolución Nacional Boliviana. La crisis de la generación dél Chaco, La Paz, Editorial Juventud, 1987, págs. 39-63. Roberto CHOOUE, "Sublevación y masacre de los comunarios de Jesús de Machaca" en Antropologia, no 1, La Paz, 1978. Silvia Rivera Cusicanoui, Oprimidos pero no vencidos. Luchas del campesinado aymara y qhechwa de Bolivia, 1900-1980, Ginebra, UNRISO, 1986. 
nos descontentos. Mientras la imagen de una guerra de razas, ahora convertida en resentimiento mestizo y, por tanto, en lucha de clases, estuviese viva, matanzas como la de los mineros de Uncia y la de los indígenas de Jesús de Machaca sólo despertarían curiosidad y permitirían al Estado presionar a la población mediante el miedo. La oposición política fue consciente de ello y no se sintió molesta porque Saavedra hubiera implantado un mayor intervencionismo estatal en las relaciones industriales, sino porque las medidas que utilizó para lograrlo implicaban una movilización de masas urbanas, manipuladas tanto contra sí mismas como contra la desposeída. Esto, unido a una distribución de puestos entre sus seguidores políticos, suponía no sólo un aumento de la corrupción electoral sino la pérdida de legitimidad del régimen de partidos políticos $\mathrm{y}$, por tanto, el control de su presencia pública.

Ante la falta de apoyo de los sectores tradicionales casi desde el comienzo de su mandato (45). Saavedra no había tenido otra alternativa que buscarlo en los sectores populares urbanos, propagando el padrinazgo y fomentando una forma de "culturalismo mestizo" que tuvo una de sus expresiones en la Guardia Republicana, un cuerpo integrado por milicias populares y por una fuerza policial paramilitar. Su origen estaba en los «club de partidos" que se crearon hacia finales del período liberal para proteger a sus dirigentes y a la prensa, asi como para disponer de fuerza de choque en las elecciones. A pesar de su rigurosa disciplina y estructura originales, la imagen política de la Guardia correspondía a una manipulación del racismo, representando la antipatía esencialmente "chola" hacia la liberal con lo que le era fácil movilizar un amplio respaldo popular, especialmente en La $\mathrm{Paz}$, y adquirir características anti-oligárquicas. Para contrarrestar la estrategia presidencial de explotar el resentimiento popular y étnico, tanto liberales como republicanos genuinos utilizaron un discurso que denigraba al "cholo y a su chusma" con la finalidad de obtener la restitución del bloque tradicional de poder a través de un programa basado en demandas democráticas y derechos constitucionales.

En conclusión, volvía a repetirse la estrategia que llevó a los liberales al poder en 1899. Si los primeros se apoyaron en la

(45) “-Fuimos, es verdad, adversarios irreductibles del gobierno del doctor Saavedra, pero reconocemos que esa actitud recalcitrante fue perjudicial para la patria, porque esterilizó la labor de un hombre de talento, seguramente bien intencionado" (Enrique FinOT, "Una obra póstuma de don Bautista Saavedra" en GómEz [2], pág. 236). 
población indigena para solventar las rivalidades entre las distintas fracciones de la élite y posibilitar a una de ellas la materialización del proyecto de reconstrucción oligárquica, Bautista Saavedra cambió al indio por el mestizo y al campesino por el proletarioartesano. Todo bajo la misma dinámica de ataque discursivo a los detentadores del poder que había sido ya utilizada por los liberales contra los conservadores. En última instancia, se defendian los términos tradicionales de las relaciones de dominación y un orden social donde indios y mestizos eran sólo instrumentos para definir las pautas de la remodelación en el interior de la élite. Por ello, la finalidad del programa de legislación para el bienestar social, que había sido defendido por el presidente ya antes del golpe de Estado, no era, asi, sólo económica, sino que pretendía reducir la militancia de la clase trabajadora en los partidos socialista y radical y alejarlos de su influencia.

La ambigüedad y oportunismo del gobierno de Bautista Saavedra volvió a manifestarse en la década de 1930 cuando el Partido Republicano formaba ya parte de la oposición. Tras la sustitución del nombre del partido por el de Partido Republicano Socialista, el 30 de septiembre de 1935 Bautista Saavedra y Edmundo Vásquez publicaron el folleto "Donde estamos; a donde debemos ir" (46). Con tales acciones, este grupo aparecía como la única fuerza política organizada de la transición, ya que representaba tanto las inquietudes reformistas de la posguerra del Chaco como las exigencias de reaparición política de los sectores tradicionales. El republicanismo saavedrista sintetizaba el esfuerzo más serio realizado por un partido tradicional para adaptarse a la crisis de las instituciones del antiguo régimen. Al recoger las inquietudes de ruptura con el antiguo régimen de los sectores reformistas y radicales que exigían la completa reversión del sistema tras el desastre de la Guerra del Chaco y al reconocer la incapacidad de la ideología liberal para conjugar la libertad individual y el bienestar colectivo, pretendía convertirse en la fuerza política hegemónica del momento. Para ello Bautista Saavedra conjugó la credibilidad de que disponía entre los sectores populares por sus esfuerzos de aproximación al sindicalismo urbano en los años 20 con la imagen de un partido de arraigo nacional y experiencia dilatada. Gracias a presentarse como el presidente de las reformas sociales y el último refugio para los tránfugas de los partidos tradicionales, se adelantó a la consolidación de los

(46) Bautista SaAvedra y Edmundo Vasouez, Dónde estamos; a dónde queremos ir. Manifiesto programa del Partido Republicano Socialista, La Paz, 1935. 
grupos reformistas de nuevo cuño y superó los esfuerzos de reconversión realizados por los liberales (47). Sin embargo, su capacidad para favorecer la adecuación de la élite a las nuevas exiencias sociales puso a la vez en peligro la continuidad de esta en la medida en que la acción republicana jugó no sólo con el enfrentamiento entre los partidos tradicionales sino que potenció las oportunidades políticas de los sectores populares. El fracaso de los mecanismos de movilización y representación política de la preguerra no se debió únicamente a su falta de adaptación sino tambien a que la élite, en su pugna y competencia por la hegemonía interna, dió ocasión de intervención pública a grupos tradicionalmente marginados de ella.

\section{CONCLUSIONES}

Con este trabajo se ha perseguido desentrañar los alineamientos históricos del proceso político contemporáneo a través del cual las élites bolivianas fueron desarrollando un conjunto de reformas institucionales y políticas encaminadas a constituir un Estado moderno pero al servicio de intereses grupales, con una participación segmentada, no plural y escasamente democrática del conjunto de la sociedad. El análisis y evaluación de estas políticas elitistas de bienestar social, en la perspectiva de una consolidación de las instituciones democráticas, impulsó una visión crítica y cuestionadora de las corrientes interpretativas dependentistas que suelen relegar la acción de las élites latinoamericanas a la condición de meros intermediarios pasivos de la dominación internacional. Más que afirmar su responsabilidad en el subdesarrollo político y económico de Iberoamérica, sería conveniente interrogarse acerca de la forma en que se pretendió dirimir el problema histórico de competencia y hegemonía en el interior de la élite.

El golpe de Estado del 12 de julio de 1920 permitió a Bautista Saavedra desarrollar una política que propició la autonomía potencial interna e internacional del Estado. El propósito central de este estudio ha sido esbozar la naturaleza del conflicto surgido entre el Estado y las élites políticas en la década de 1920. El

(47) Ferrán Gal.tego. Los origenes del reformismo militar én América Latina. La gestión de David Toro én Bolivia. Barcelona, ed. PPU, 1991, págs. 37-44. "Estado, nación, reforma. Las paradojas del nacionalismo boliviano en los años treinta", en Boletin Americanista, no 41, Barcelona, 1991. 
argumento principal que se desprende del análisis presentado es que la lucha por el poder en el interior de la élite boliviana condicionó el comportamiento del resto de los grupos sociales, en la medida en que la finalidad expresa de un reajuste partidario, basado en el golpe de Estado y en el apoyo de clientelas políticas, fue lograr un sistema político favorable a su proyecto de reconversión. Pero ese objetivo produjo el efecto contrario al trasladar la inestabilidad y conflicto entre estos grupos del poder a una confrontación entre Estado y élites, que se manifestó en la institucionalización de las clientelas políticas que favorecieron el ascenso social controlado de los grupos subalternos. La década de 1920 marcó, entonces, el inicio de una estrategia de dominación basada en una política de consenso y cooperativismo que permitió que fueran los grupos subalternos los principales sostenedores de las relaciones de poder. Su participación no significó una democratización del sistema sino un redecrudecimiento del autoritarismo. El enfrentamiento intra-élites potenció las rivalidades entre los distintos sectores sociales hasta el punto de generar resistencias con capacidad de remodelarla, pero no de transgredirla. Esta ambigüedad posibilitó el surgimiento a partir de la lucha intraélites de las ideas acerca de lo nacional-popular que retomarán más tarde partidos como el MNR (Movimiento Nacional Revolucionario), el PIR (Partido de Izquierda Revolucionaria) y el POR (Partido Obrero Revolucionario). Por este motivo, la quiebra del bloque tradicional en la década de los treinta no resumió tanto el agotamiento del modelo de régimen partidario surgido en 1880 como el hecho de que su caída conllevó la repetición de un modelo de autoridad legitimado por el uso formal de discursos «revolucionarios». 